\title{
Mechanism of End Breakage due to Knots in Weft Knitting Zone Part 1 : End Breakage in Plain-weft Knitting Zone
}

\author{
Ryuzo Oinuma*, Shinji Nishimura** and Tony Madeley*** \\ * Miyagi University of Education, Sendai \\ **Kumamoto Technical High School, Kumamoto \\ ***Department of Textile Technology, University of New South Wales, Sydney, Australia
}

Based on the Journal of the Textile Machinery Society of Japan, Vol.48, No.7, T173-T182(1995-7)

Abstract

The mechanism of the end breakage due to knots (a weaver's knot and a fisherman's knot using a combed cotton yarn c30s/1 cotton count) in the plain-weft knitting zone is investigated in detail, using a high speed video camera.

The results obtained are as follows :

(1) It clarifies that the end breakage due to knots in the plain-weft knitting zone occurs in the following three steps : 1) jam of knots in the space between a needle-hook and -latch and an old loop, or in the space between a needle-head and a verge, 2) increase in the yarn tension, 3 ) end breakage due to knots.

(2) The end breakage due to an air-splice in the plain-weft knitting zone hardly occurs under every knitting condition.

(3) The rate of jammed knots, the end breakage rate for jammed knots and that for knots increase with the increase of the depth of stitch draw, the input tension and the take-down weight for any knot.

(4) The rate of jammed knots, the end breakage rate for jammed knots and that for knots due to a fisherman's knot are always more than those due to a weaver's knot under every knitting condition.

\section{Introduction}

Faults of spun yarns such as slubs and neps reduce the knitting efficiency and the quality of knitted fabrics ${ }^{1)}$. Therefore, these are cut out and replaced by knots in winding. The number of knots made in the winding process reached $19-44$ in a cone(net weight $1.5 \mathrm{~kg})^{2}$. In the weft knitting of spun yarns having many knots, the end breakage due to knots is a serious problem in view of the knitting efficiency and the quality of knitted fabrics ${ }^{2,3)}$. However, few works have been reported on the subject of weft knitting.

The author ${ }^{4,5)}$ has shown the effect of some factors on the end breakage rate due to a weaver's knot in the plain-weft knitting zone and then the comparison of the end breakage due to an splice and knots(a weaver's knot and a fisherman's knot) in the plain-weft knitting zone.

This paper attempts to consider the mechanism of the end breakage due to knots(a weaver's knot and a fisherman's knot) in the plain-weft knitting zone using a high speed video camera.

\section{Experimental}

\subsection{Details of yarn joints}

A Mesdan air-splicer(Jointair 04C) or a mechanical knotter (Weaver's knotter A/775 or Fisherman's knotter 815-A) was mounted on a Kamimat automatic winder \#550. The knitting yarn used was a combed cotton yarn c30s/1 cotton count (19.7 tex) and was tied in about 50 joints(an airsplice, a weaver's knot and a fisherman's knot). The air blast duration and the tail trimming length may be altered in the Jointair. The blest-indicator was set at 4 and the tailindicator at 2 .

The profiles of a cotton yarn, an air-splice, a weaver's knot and a fisherman's knot are illustrated in Figure 1.

An air-splice is fuzzy, but it does not have a knot tail and is a knot-free joint. Therefore, an air-splice is a smooth yarn joint compared with other knots. Although both tails of a weaver's knot point in the same direction, the direction of the tails of a fisherman's knot is opposite to each other.

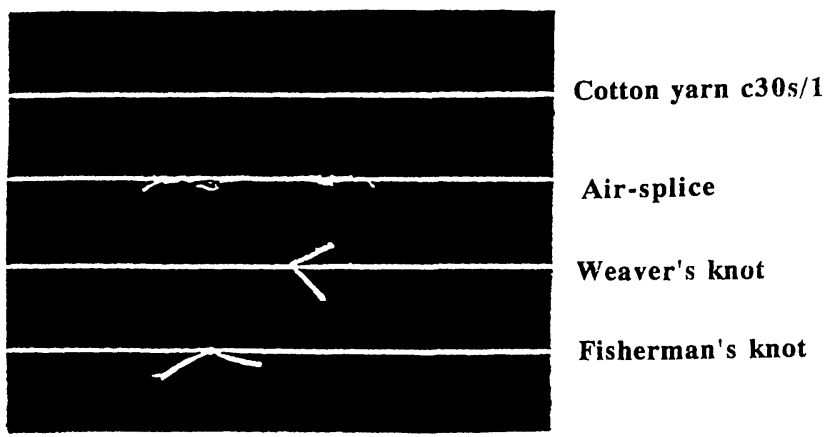

Fig.1 Yarn and knot profiles of a cotton yarn

The diameters of a cotton yarn, an air-splice, a weaver's knot and a fisherman's knot were measured 300 times using a profile projector and a slub catcher respectively.

The diameters of a cotton yarn(NY), an air-splice(AS), a weaver's $\operatorname{knot}(\mathrm{WK})$ and a fisherman's $\operatorname{knot}(\mathrm{FK})$ are shown in Table 1.

A tensile tester was used to measure the breaking strength and elongation of a cotton yarn, an air-splice, a weaver's knot and a fisherman's knot 100 times respectively. The joint was placed midway between the jaws, the gauge length set at $100 \mathrm{~mm}$ and the tensile speed at $100 \mathrm{~mm} / \mathrm{min}$.

The breaking strength(BS) and elongation(BE) of a cotton yarn, an air-splice, a weaver's knot and a fisherman's knot are shown Table 2. 
Table 1 Diameters of a cotton yarn and three yarn joints

\begin{tabular}{c|ccc|ccc}
\hline \multirow{2}{*}{$\begin{array}{c}\text { Yarn } \\
\text { joints }\end{array}$} & \multicolumn{3}{|c|}{ Profile projector } & \multicolumn{3}{c}{ Slub catcher } \\
\cline { 2 - 7 } & $\begin{array}{c}\text { Mean } \\
(\mathrm{mm})\end{array}$ & $\begin{array}{c}\text { Min-Max } \\
(\mathrm{mm})\end{array}$ & $\begin{array}{c}\text { C.V. } \\
(\%)\end{array}$ & $\begin{array}{c}\text { Mean } \\
(\mathrm{mm})\end{array}$ & $\begin{array}{c}\text { Min-Max } \\
(\mathrm{mm})\end{array}$ & $\begin{array}{c}\text { C.V. } \\
(\%)\end{array}$ \\
\hline NY & 0.177 & $0.119-0.248$ & 13.6 & - & - & - \\
AS & 0.354 & $0.227-0.485$ & 11.9 & 0.245 & $0.17-0.33$ & 12.7 \\
WK & 0.489 & $0.300-0.658$ & 10.6 & 0.363 & $0.28-0.48$ & 10.3 \\
FK & 0.530 & $0.425-0.766$ & 10.0 & 0.417 & $0.30-0.50$ & 13.5 \\
\hline
\end{tabular}

C.V. : Coefficient of variation.

Table 2 Breaking strength and elongation of jointed yarn

\begin{tabular}{c|ccc|ccc}
\hline \hline \multirow{2}{*}{$\begin{array}{c}\text { Yarn } \\
\text { joints }\end{array}$} & \multicolumn{3}{|c|}{ Breaking strength } & \multicolumn{3}{c}{ Breaking elongation } \\
\cline { 2 - 7 } & $\begin{array}{c}\text { Mean } \\
\text { (gf) }\end{array}$ & $\begin{array}{c}\text { C.V. } \\
(\%)\end{array}$ & Rs & Mean & C.V. & Re \\
\hline NY & 295.5 & 10.2 & - & 6.37 & 6.5 & - \\
AS & 180.2 & 13.0 & 0.61 & 7.06 & 9.9 & 1.11 \\
WK & 282.9 & 11.2 & 0.96 & 6.34 & 7.4 & 1.00 \\
FK & 293.1 & 10.4 & 0.99 & 6.20 & 9.9 & 0.97 \\
\hline
\end{tabular}

C.V. : Coefficient of variation.

Rs=BS of jointed yarn/BS of normal yarn.

$\mathrm{Re}=\mathrm{BE}$ of jointed yarn/BE of normal yarn.

\subsection{Details of knitting}

A 6-feeder, 696-needle(22 gauge), 10-in. diameter circular rib knitting machine was used with a positive-yarn-feeding device(IRO system). To manufacture plain-weft knitted fabrics only, the machine was stripped of all unnecessary parts (the dial, its support and the take-down mechanism). The input tension was controlled by a positive-yarn-feeding device and measured with a yarn tension meter before the yarn enters the feeder. To ensure a constant take-down tension, a deadweight was tied to the fabric. To take the photograph of the knitting behavior using a high speed video camera, the knitting machine speed was reduced $2.7 \mathrm{rev} . / \mathrm{min}$ using the Ringcone variable speed drive. The cam angle was set at $50.0^{\circ}$, and the step length of cam at $3.20 \mathrm{~mm}$.

The dimensions of knitting elements are shown in Table 3.

Table 3 Dimensions of knitting elements

\begin{tabular}{c|c}
\hline Knitting elements & 22 gauge \\
\hline Thickness of needle $(\mathrm{mm})$ & 0.34 \\
Thickness of verge $(\mathrm{mm})$ & 0.40 \\
Needle spacing $(\mathrm{mm})$ & 1.15 \\
\hline
\end{tabular}

Each set of fabrics was knitted under various knitting conditions. Each fabric raveled and the course length was measured 30 times using a course length tester under $10 \mathrm{~g}$ weight. The loop length is the value of the mean course length divided by the number of cylinder needle.

\subsection{Observation of end breakage}

The yarn consisting of about 50 joints was fed to one feeder only. Photographs were taken of the knitting of each plain-weft knitted fabric under various knitting conditions with a high speed video camera(the camera speed at 200 frames/sec). Six frames can be taken of the knitting behavior as the needle moves one needle spacing.

The process of end breakage due to knots in the knitting zone was observed and the number of $\operatorname{knots}\left(N_{k}\right)$, that of jammed $\operatorname{knots}\left(N_{j}\right)$ and that of end breakage due to $\operatorname{knots}\left(N_{e}\right)$ were counted by playing back of photographs of the knitting behavior. The judgment of end breakage due to knots was made by the observation of the loss of a loop on the needle after one revolution of the knitting machine.

The rate of jammed $\operatorname{knots}\left(R_{j}\right)$, the end breakage rate for jammed $\operatorname{knots}\left(R_{e}\right)$ and that for $\operatorname{knots}(E B R)$ are given as percentages by :

$$
\begin{aligned}
& R_{j}(\%)=\left(N_{j} / N_{k}\right) \times 100 \\
& R_{j}(\%)=\left(N_{e} / N_{j}\right) \times 100 \\
& E B R(\%)=\left(N_{e} / N_{k}\right) \times 100
\end{aligned}
$$

\section{Results and Discussion}

\subsection{Process of end breakage due to knots}
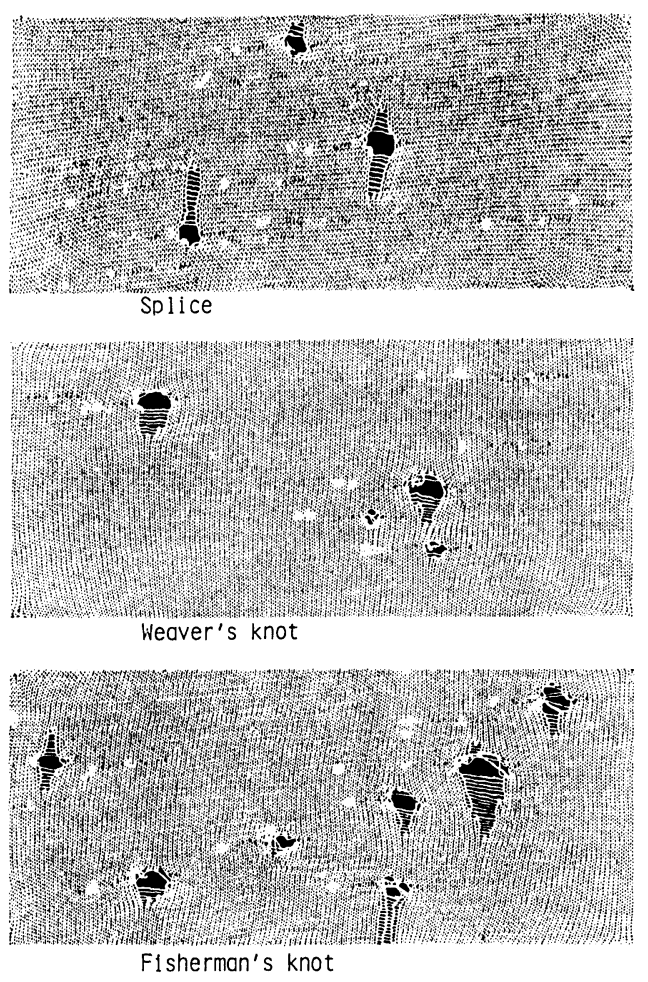

Fig 2 Knitting holes due to joints 


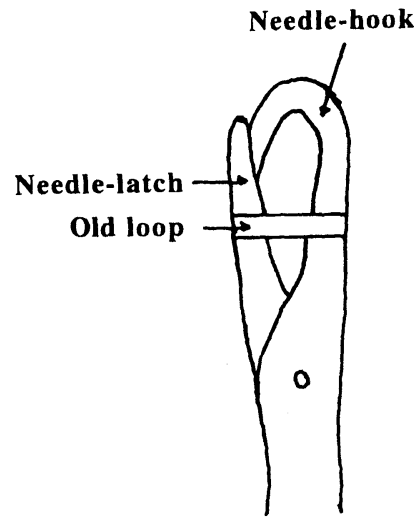

(1)

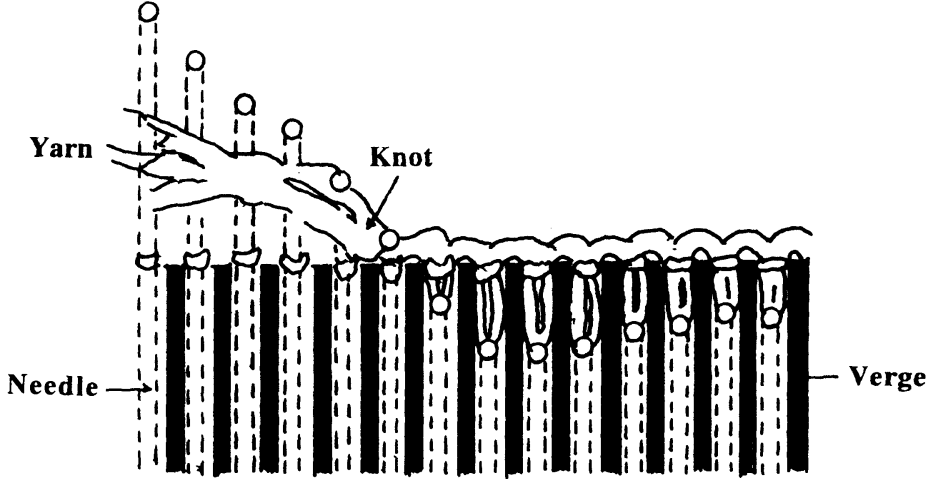

(2)

Fig.3 Schematic diagram of jam of knot in the space

(1) The space between a needle-hook and -latch and an old loop

(2) Jam of knot in the space between a needle-hook and -latch and an old loop

Table 4 Process of end breakage due to a weaver's knot

\begin{tabular}{|c|c|}
\hline No. & Explanation of process of endbreakage \\
\hline 1 & The knot enters the knitting zone. \\
\hline 2 & The knot approaches the marked needle. \\
\hline Between 2 and 3 & $\begin{array}{l}\text { The knot jams in the space between a needle-hook and -latch and an old } \\
\text { loop. }\end{array}$ \\
\hline Between 3 and 5 & The knot is in contact with the marked needle-head and descends with that. \\
\hline Between 5 and 6 & End breakage occurs on the right side of the marked needle. \\
\hline Between 6 and 7 & $\begin{array}{l}\text { The knot separates gradually from the marked needle-head and moves } \\
\text { upwards. The loops held by the marked needle and the right neighboring } \\
\text { needle are loosened gradually. }\end{array}$ \\
\hline 8 & The marked needle reaches the knitting point. \\
\hline Between 8 and 11 & $\begin{array}{l}\text { The marked needle moves parallel on the step of the cam. The broken parts } \\
\text { of the loops held by the marked needle and the right neighboring needle are } \\
\text { spread gradually and the loops holding those finally disappeared. }\end{array}$ \\
\hline 12 & $\begin{array}{l}\text { The marked needle and the right neighboring needle can not ascend } \\
\text { because of the end breakage. }\end{array}$ \\
\hline
\end{tabular}

The knitting defects(knitting holes) due to joints on the plain-weft knitted fabrics are illustrated Figure 2.

Figure 2 shows that the thick places occur on both sides of the knitting hole due to an air-splice. The knot remains on the left side of knitting hole due to both types of knot. Therefore, it is considered that end breakage due to an airsplice occurs a part of the air-splice and that due to knots occurs near the knot on the take-down side only.

Making an observation using a high speed camera shows that an air-splice hardly causes any end breakage in the knitting zone under any knitting condition.

The schematic diagrams of the space between a needle-hook and -latch and an old loop, and the jam of knot in the space in the knitting zone are shown in Figure 3(1) and (2).
The process of end breakage due to both a weaver's knot and a fisherman's knot in the knitting zone is shown in Figures 4 and 5 respectively.

From Figures 4 and 5, the end breakage due to a weaver's knot and a fisherman's knot in the knitting zone occurs similarly. The process of end breakage due to a weaver's knot may therefore be described as below.

The numbers in Figures 4 and 5 express the order of the knitting process, but 2 frames skip from 1 to 11 and 8 frames from 11 to 12 . The needle below the mark $\nabla$ is always the same needle.

Figure 3(2) is a schematic diagram of frame 2 in Figure 4. In Figure 3(2), the needle descends from the left-hand end to the knitting point and moves parallel on the step of the cam 


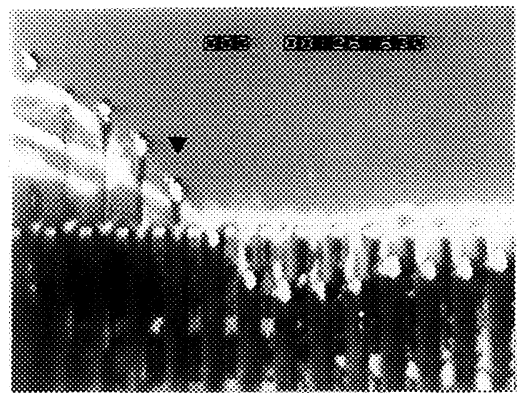

1

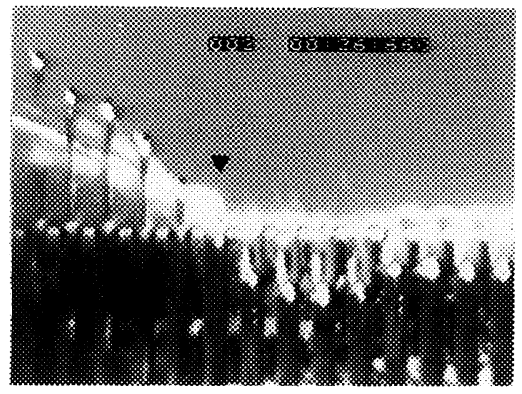

4

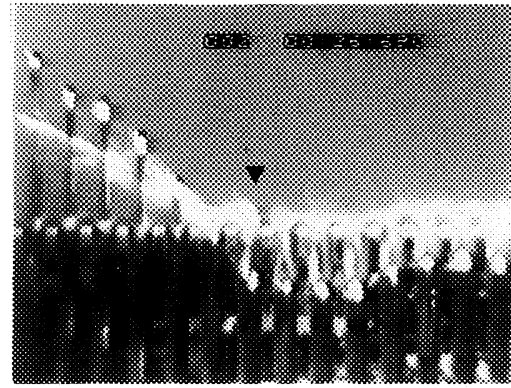

7

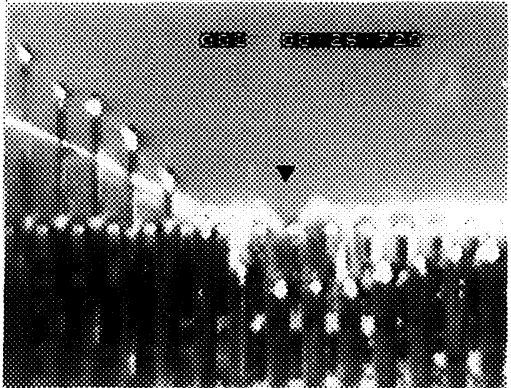

10

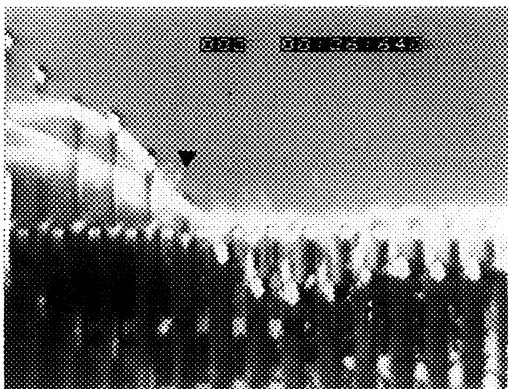

2

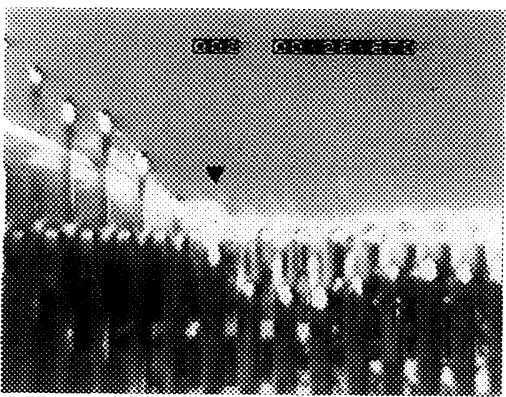

5

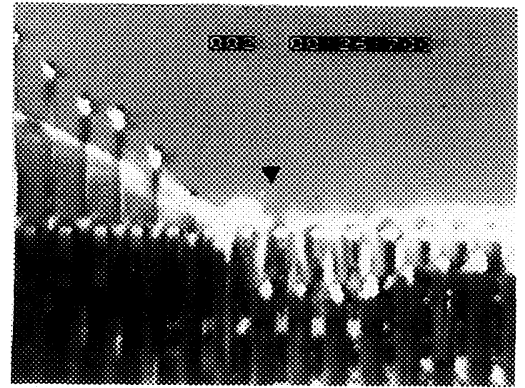

8

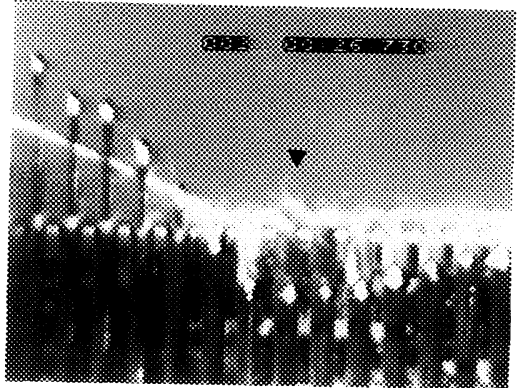

11

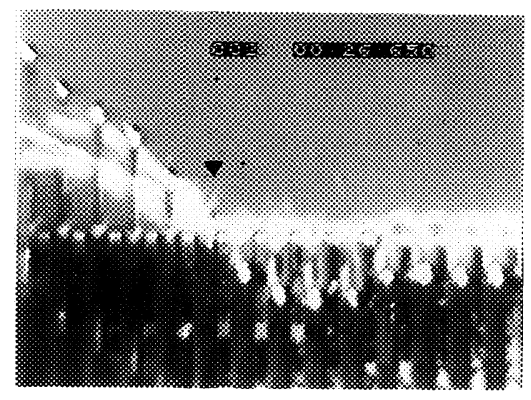

3

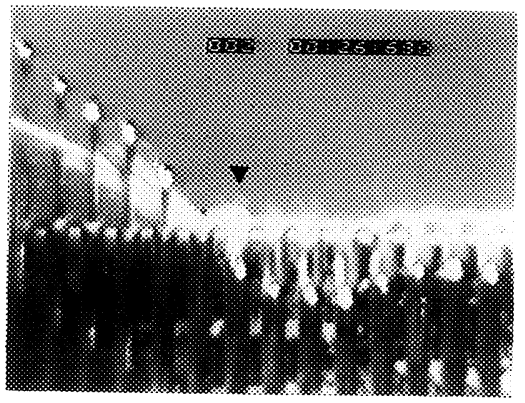

6

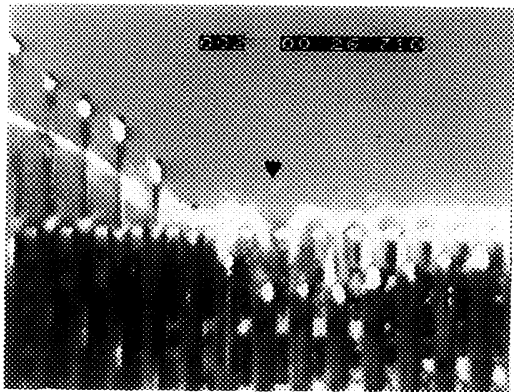

9

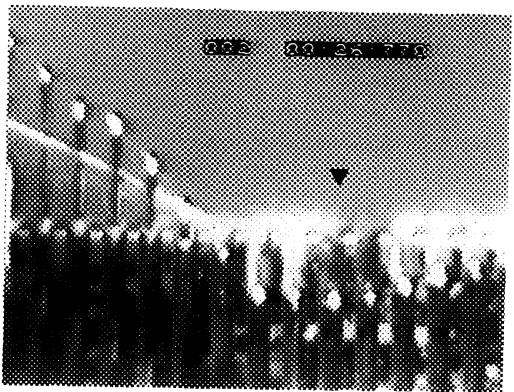

12

Fig.4 Process of end breakage due to a weaver's knot

between about three needle spacing and then ascends.

Explanation of the process of end breakage due to a weaver's in the knitting zone is shown in Table 4. Table 4 should be read in connection with Figure 4.

\subsection{Jamming of knots and end breakage}

From the observation of the process of end breakage due to knots(Figures 3 and 4), jamming of knots occurs at the space between a needle-hook and -latch and an old loop.
This space decreases with the descent of a needle. When this space becomes smaller than the dimension of the knot, the knot jams in this space.

A schematic diagram of the plain-weft knitting zone is shown in Figure 6.

It is considered that the state of Figure 6 is the initial state of the jam of a weaver's knot. If the knot located in the yarn fed between the needles $N_{1}$ and $N_{2}$ move from the initial state of the jam to the knitting point, it will jam in the space between a needle-hook and -latch and an old loop or in 


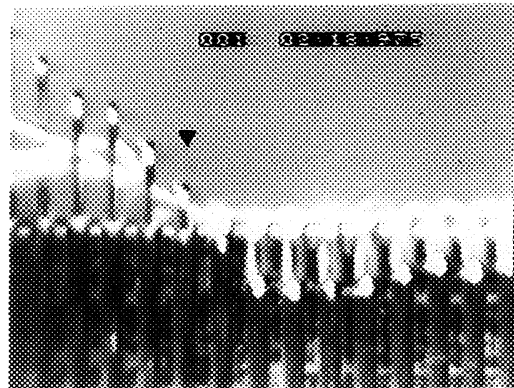

1

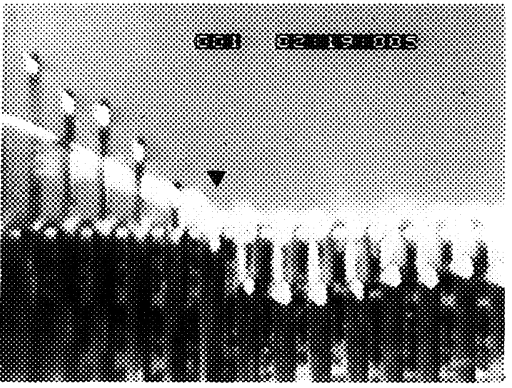

4

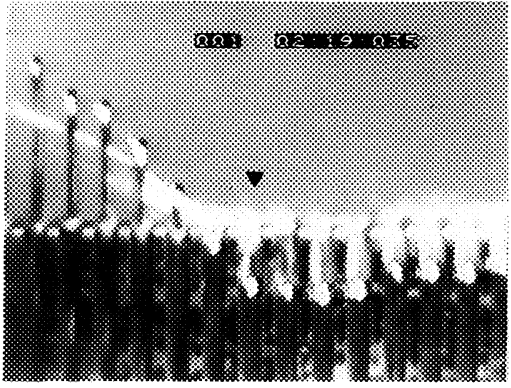

7

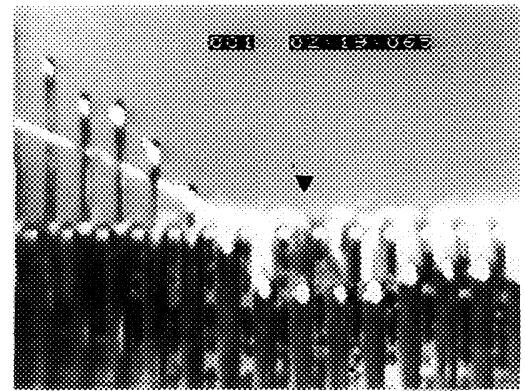

10

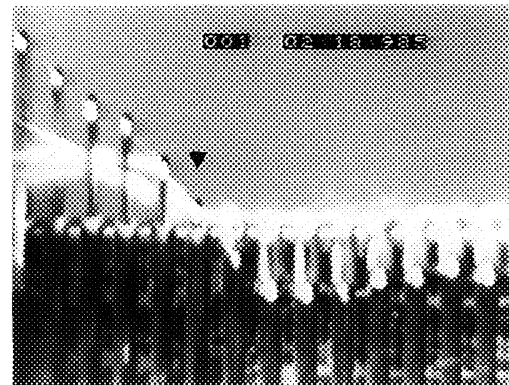

2

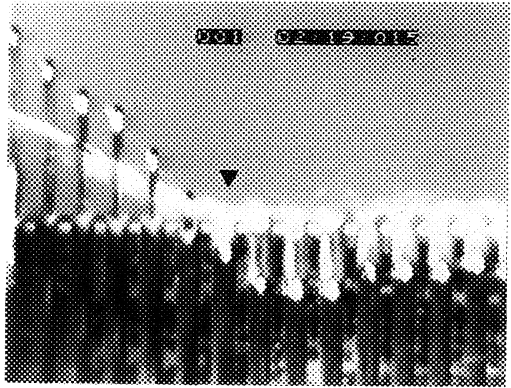

5

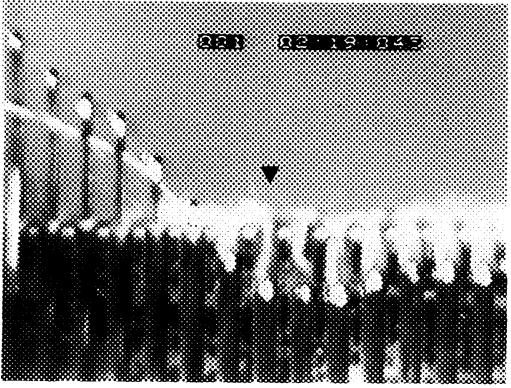

8

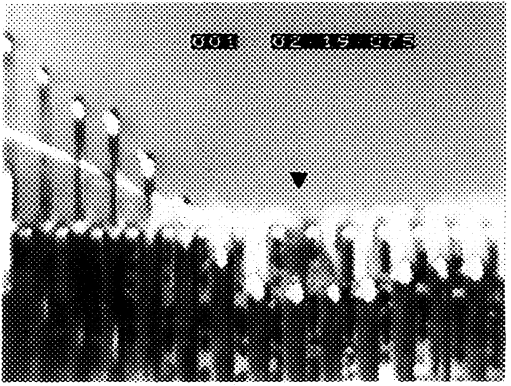

11

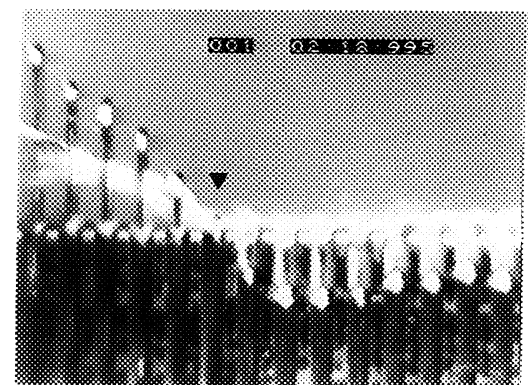

3

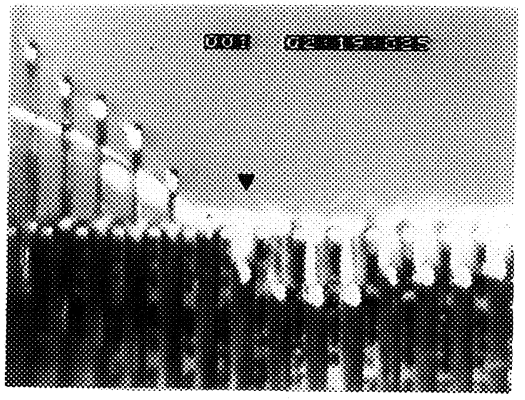

6

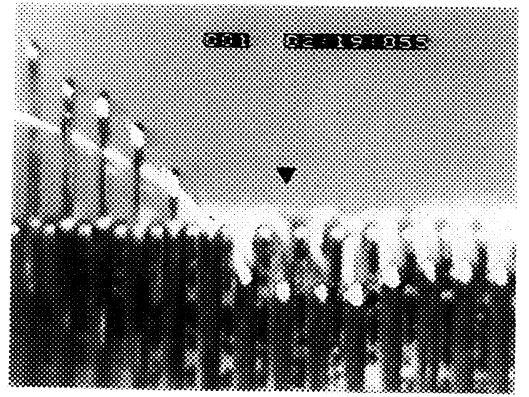

9

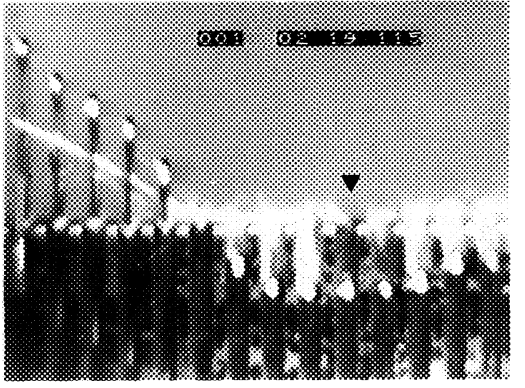

12

Fig.5 Process of end breakage due to a fisherman's knot

the space between a needle-head and a verge.

Let $l$ be the yarn fed between the needles $N_{1}$ and $N_{2}$ moving from the initial state of the jam to the knitting point and $L$ be the loop length, the rate of jammed knots is dependent on the value of $l / L$.

End breakage occurs at any point in section $a b$ or $c d$. The end breakage in section $a b$ is about $87 \%$ for a weaver's knot and about $69 \%$ for a fisherman's knot, and that in section $c d$ is about $13 \%$ for a weaver's knot and about $29 \%$ for a fishman's knot.
The depth of stitch draw is represented by the vertical distance between the upper surface of a verge and the knitting point as shown in Figure 6.

The variation of the rate of jammed $\operatorname{knots}\left(R_{j}\right)$, the end breakage rate for jammed $\operatorname{knots}\left(R_{e}\right)$ and the end breakage rate for $\operatorname{knots}(E B R)$ with the depth of stitch draw is shown in Table 5.

$R_{j}, R_{e}$ and $E B R$ due to both knots increase with the increase of the depth of stitch draw. The loop length increases with the increase of the depth of stitch draw. $R_{j}$ increases 


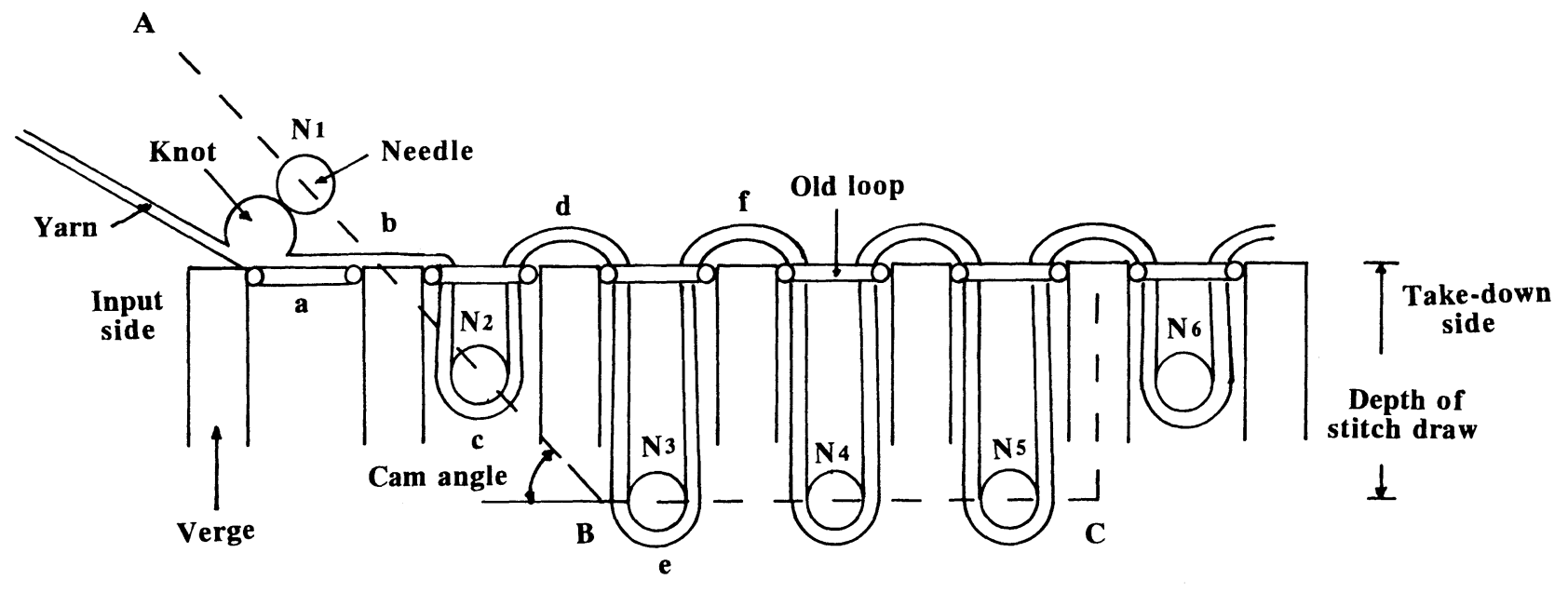

Fig.6 Schematic diagram of plain-weft knitting zone $\mathrm{ABC}$; Sharp of stitch cam, BC ; Step length of cam, B ; Knitting point

Table 5 Effect of depth of stitch draw on $R_{j}, R_{e}$ and $E B R$

\begin{tabular}{c|cccccccc}
\hline \hline $\begin{array}{c}\text { Kind } \\
\text { of } \\
\text { knot }\end{array}$ & $\begin{array}{c}\text { Stitch } \\
\text { draw }\end{array}$ & $\begin{array}{c}\text { Loop } \\
\text { length } \\
(\mathrm{mm})\end{array}$ & $N_{k}$ & $N_{j}$ & $\begin{array}{c}R_{j} \\
(\%)\end{array}$ & $N_{e}$ & $\begin{array}{c}R_{e} \\
(\%)\end{array}$ & $\begin{array}{r}E B R \\
(\%)\end{array}$ \\
\hline \multirow{4}{*}{ WK } & 1.2 & 4.02 & 52 & 29 & 55.8 & 16 & 55.2 & 30.8 \\
& 1.4 & 4.45 & 51 & 38 & 74.5 & 29 & 76.3 & 56.9 \\
& 1.6 & 4.81 & 61 & 46 & 75.4 & 36 & 78.3 & 59.0 \\
\hline & 1.2 & 4.02 & 56 & 46 & 82.1 & 34 & 73.9 & 60.7 \\
FK & 1.4 & 4.45 & 47 & 40 & 85.1 & 34 & 85.0 & 72.3 \\
& 1.6 & 4.81 & 67 & 60 & 89.6 & 54 & 90.0 & 80.6 \\
\hline
\end{tabular}

WK:Weaver's knot, FK:Fisherman's knot, Input tension:5.0 gf, Take-down weight: $6.6 \mathrm{~kg}$.

with the increase of the depth of stitch draw, probably due to the increase of the value of $l / L . R_{e}$ and $E B R$ increase with the increase of the depth of stitch draw, so the value of $l / L$ and the yarn tension in sections $a b$ and $c d$ increase with that of the depth of stitch draw.

The variation of the rate of jammed $\operatorname{knots}\left(R_{j}\right)$, the end breakage rate for jammed $\operatorname{knots}\left(R_{e}\right)$ and the end breakage rate for $\operatorname{knots}(E B R)$ with the input tension is shown in Table 6.

$R_{j}, R_{e}$ and $E B R$ due to both knots increase with the increase of the input tension. The loop length decreases with the increase of the input tension. $R_{j}$ increases with the increase of the input tension, probably due to the increase of the value of $l / L . R e$ and $E B R$ increase with the increase of the input tension, so the value of $l / L$ and the initial yarn tension in sections $a b$ and $c d$ increase with that of the input tension.

The variation of the rate of jammed $\operatorname{knots}\left(R_{j}\right)$, the end breakage rate for jammed $\operatorname{knots}\left(R_{e}\right)$ and the end breakage rate for $\operatorname{knots}(E B R)$ with the take-down weight is shown in
Table 6 Effect of input tension on $R_{j}, R_{e}$ and $E B R$

\begin{tabular}{c|cccccccc}
\hline $\begin{array}{c}\text { Kind } \\
\text { of } \\
\text { knot }\end{array}$ & $\begin{array}{c}\text { Input } \\
\text { tension } \\
(\mathrm{mm})\end{array}$ & $\begin{array}{c}\text { Loop } \\
\text { length } \\
(\mathrm{mm})\end{array}$ & $N_{k}$ & $N_{j}$ & $\begin{array}{c}R_{j} \\
(\%)\end{array}$ & $N_{e}$ & $\begin{array}{c}R_{e} \\
(\%)\end{array}$ & $\begin{array}{c}E B R \\
(\%)\end{array}$ \\
\hline & 5.0 & 4.02 & 52 & 29 & 55.8 & 16 & 55.2 & 30.8 \\
WK & 10.0 & 3.98 & 47 & 33 & 70.2 & 25 & 75.8 & 53.2 \\
& 15.0 & 3.90 & 41 & 31 & 75.6 & 24 & 77.4 & 58.5 \\
\hline & 5.0 & 4.02 & 56 & 46 & 82.1 & 34 & 73.9 & 60.7 \\
FK & 10.0 & 3.98 & 32 & 28 & 87.5 & 23 & 82.1 & 71.9 \\
& 15.0 & 3.90 & 70 & 62 & 88.6 & 53 & 85.5 & 75.7 \\
\hline
\end{tabular}

WK:Weaver's knot, FK:Fisherman's knot,

Depth of stitch draw:1.2 mm, Take-down weight:6.6 kg.

Table 7.

$R_{j}, R_{e}$ and $E B R$ due to both knots increase with the increase of the take-down weight. The take-down weight has hardly any effect on the loop length. $R_{j}$ increases with the increase of the take-down weight, probably due to the increase of the value of $l / L . R_{e}$ and $E B R$ increase with the increase of the take-down weight, so the value of $l / L$ increases and \%RB (the percent robbing back) decreases with that of the take-down weight.

$R j, R_{e}$ and $E B R$ due to a fisherman's knot are always more than those due to a weaver's knot under every knitting condition.

The state of each type of knot both normal and squeezed with fingers is shown in Figure 7.

From Figure 7, the thickness of a weaver's knot squeezed with fingers is equal to that of the normal state of a weaver's knot. Since the direction of the tails of a fisherman's knot is opposite to each other, the thickness of a fisherman's knot squeezed with fingers is the sum of the diameter of the yarn and the knot as shown in Figure 7. It is 
Table 7 Effect of take-down weight on $R_{j}, R_{e}$ and $E B R$

\begin{tabular}{c|cccccccc}
\hline \hline $\begin{array}{c}\text { Kind } \\
\text { of } \\
\text { knot }\end{array}$ & $\begin{array}{c}\text { TD } \\
\text { weight } \\
(\mathrm{mm})\end{array}$ & $\begin{array}{c}\text { Loop } \\
\text { length } \\
(\mathrm{mm})\end{array}$ & $N_{k}$ & $N_{j}$ & $\begin{array}{c}R_{j} \\
(\%)\end{array}$ & $N_{e}$ & $\begin{array}{c}R_{e} \\
(\%)\end{array}$ & $\begin{array}{c}E B R \\
(\%)\end{array}$ \\
\hline & 4.0 & 4.02 & 49 & 26 & 53.1 & 11 & 42.3 & 22.4 \\
WK & 6.6 & 4.02 & 52 & 29 & 55.8 & 16 & 55.2 & 30.8 \\
& 8.0 & 4.03 & 46 & 28 & 60.9 & 16 & 57.1 & 34.8 \\
\hline & 4.0 & 4.02 & 47 & 38 & 80.9 & 20 & 52.6 & 42.6 \\
FK & 6.6 & 4.02 & 56 & 46 & 82.1 & 34 & 73.9 & 60.7 \\
& 8.0 & 4.03 & 53 & 46 & 86.8 & 36 & 78.3 & 67.9
\end{tabular}

WK:Weaver's knot, FK:Fisherman's knot, TD:Take-down,

Depth of stitch draw:1.2 mm, Input tension:5.0 gf.

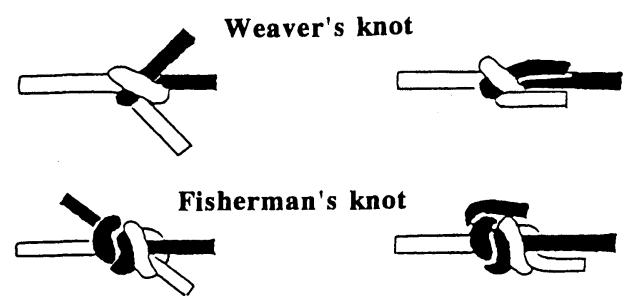

Normal state of knot

State of knots squeezed with a finger

Fig.7 Knots of normal and squeezed with fingers

considered that $R_{j}, R_{e}$ and $E B R$ due to a fisherman's knot is always more than those due to a weaver's knot, so the thickness of a fisherman's knot is larger than that of a weaver's knot.

\subsection{Mechanism of end breakage due to knots in plain-weft knitting zone}

From Figures 2-6 and result of 3.2, it is clear that the end breakage due to knots in the knitting zone occurs in the following three steps. Using Figure 6 , therefore, the mechanism of the end breakage due to knots in the knitting zone may be described as below.

(1) Jam of knots in the space : The space between a needlehook and -latch and an old loop(Figures 3-6) decreases with the descent of the needle $N 1$. When the space becomes smaller than the thickness of a knot, the knot jams in the space. This state continues until the needle $N 1$ reaches the knitting point.

(2) Increase of yam tension : When the knot jams in the space, the yarn from the input side is not fed into sections $a b, b c$ and $c d$. Since the increase of yarn length in sections $a b, b c$ and $c d$ with the descent of the needles $N_{1}$ and $N_{2}$ has to be compensated by yarn elongation and robbing-back, the yarn tension in sections $a b, b c$ and $c d$ increases rapidly. (3) End breakage : When the yarn tension in section $a b$ or $c d$ becomes larger than the breaking strength of a knotted yarn, the end breakage due to a knot occurs at any point in section $a b$ or $c d$, that is, near the knot on the take-down side.

\section{Conclusion}

The mechanism of the end breakage due to joints(an airsplice, a weaver's knot and a fisherman's knot using a combed cotton yarn c30s/ 1 cotton count) in the plain-weft knitting zone is investigated in detail, using a high speed video camera.

By playing back of photographs of the knitting behavior, the process of end breakage due to knots was observed and the number of knots, that of jammed knots and that of end breakage due to knots were counted.

The results obtained are as follows :

(1) By observation using a high speed video camera, the end breakage due to an air-splice in the knitting zone hardly occurs under every knitting condition.

(2) The rate of jammed knots, the end breakage rate for jammed knots and that for knots increase with the increase of the depth of stitch draw, the input tension and the takedown weight for any knot.

(3) The rate of jammed knots, the end breakage rate for jammed knots and that for knots due to a fisherman's knot are always more than those due to a weaver's knot under every knitting condition.

(4) It clarifies that the end breakage due to knots in the knitting zone occurs in the following steps.

1) Jam of knots in the space: The space between a needlehook and -latch and an old loop decreases with the descent of the needle. When the space becomes smaller than the thickness of a knot, the knot jams in the space. This state continues until the needle reaches the knitting point.

2) Increase of yam tension: When the knot jams in the space, the yarn from the input side is not fed into sections $a b, b c$ and $c d$. Since the increase of yarn length in sections $a b, b c$ and $c d$ with the descent of the needles $N_{1}$ and $N_{2}$ has to be compensated by yarn elongation and robbing-back, the yarn tension in sections $a b, b c$ and $c d$ increases rapidly.

3) End breakage : When the yarn tension in section $a b$ or $c d$ becomes larger than the breaking strength of a knotted yarn, the end breakage due to a knot occurs at any point in section $a b$ or $c d$, that is, near the knot on the take-down side.

\section{References}

(1) "Meriyasu Gijutsu Hikkei(Yokoami Hen), p.112, p.267, The Textile Machinery Society of Japan, Osaka(1971)

(2) O.Bissmann; Int.Text.Bull.(Weaving), p.233(1981)

(3) P.Mehta; Knit.Tim., 40, No.19, 39(1971)

(4) R.Oinuma; J.Text.Mach.Soc.Japan(Eng.), 32, 36(1986)

(5) R.Oinuma, E.Sasaki and H.Suzuki ; J.Text.Mach.Soc. Japan(Eng.), 37, 73(1991) 